\title{
The effects of the relaxation exercises in the case of the children with learning difficulties
}

\begin{tabular}{c} 
Magdalena Dumitrana \\
Adventus University, Cernica, Romania \\
\hline
\end{tabular}

ABSTRACT
The paper discusses the possibility of the obtaining of beneficial effects through a relaxation exercise pro-
gram comprising children with mental disabilities. Based on the literature in the field, the question arises to
what extent these exercises can take place under less favorable conditions, that is even in the classroom.

\section{INTRODUCTION}

Our era is already familiar with different types of relaxation, most of them being taken (read deformed) from the Far East. We mention from the beginning, this article is delimited by so-called yoga teachers, meditation, personal development, etc. and refers strictly to the area of medicine and psychology.

We will also refer only to the cases involving children, namely children with intellectual disabilities. Among other difficulties they face in their efforts to adapt to daily life, anxiety, problems in psycho-motor coordination, aggressivity are very visible in their behavior.

In terms of psychotherapy, the interest for these children is not too old; however, once the need for psychomotor relaxation was noted in general, in children with difficulties in particular, things evolved rapidly. In this context, we can outline three directions of action which, over time, have borrowed from each other different techniques, adapted to the problems of the subjects.

Thus, there are three main directions for working with children with mental disabilities:

- Relaxation therapy in clinical psychology;

- Therapy with the help of oriental techniques: Yoga (we speak exclusively of Hatha-Yoga) and traditional Chinese exercises;

- Autogenic training.
Regarding the first direction, in 1972, J. Destrooper and P. Vayer (1) presented a new relaxation program with two subjects, two boys aged 14 and 10, admitted to a psychiatric hospital (Rivière des Prairies in Montreal), presenting a severe mental impairment, behavioral disorders, language disorders and aggressivity.

Both children, from different families, were placed in institutions very early - one from the age of 5 , the other from the moment of the abandonment at birth. The medical treatment had no positive effects. The program was held for two months in the psychology laboratory of the hospital, where the children were brought from their wards.

Through bodily contact with the adult (supporting the child movements) a state of relaxation was obtained which allowed the children to perform afterwards, the required exercises (always from the lying down position). Also, the boys were trained to coordinate their movements with their breath.

In both subjects, the disappearance of the psychomotor agitation was observed; they became calmer and consequently, more attentive regarding the therapeutic activities.

Considering also some other positive effects for each of the two subjects, the authors recommend the introduction of psychosomatic therapy among the commonly used educational techniques. 
Of course, in the cases discussed, one cannot speak of positive long-term effects - the family history of the two subjects, the multitude of health problems and the institutional environment in which they were sentenced to live their entire lives, all of these factors were still there.

The study, however, opened an interesting perspective regarding the possibility of applying the muscle relaxation exercises to the persons with disabilities. From here, there was a start from building relaxation programs applicable to people with mental disabilities, especially adults, such as Progressive Muscle Relaxation or Abbreviated Progressive Relaxation, programs that started from the hypothesis that, by relaxing the skeletal muscles muscles, one can reach the mind and the body relaxation.

A second direction of psycho-relaxation therapy is represented by the exercises borrowed from Hatha-Yoga - postures and breathing.

Classics in this area are Charles Wattelle's volumes $(2,3)$. In 1975 he published his first book on Yoga, „Yoga et handicaps mentaux“, and in 1983 he wrote a second book, ,Yoga, troubles et Handicaps". Having practiced yoga for many years, he found that there is a certain parallel between the states of discomfort of a normal person and those of a mentally handicapped one. Thus, he develops a set of Hatha Yoga exercises accessible to those people having intellectual disability, including breathing, relaxation, vibration (of the chest) and equilibrium. The purpose was to establish a certain physical and mental balance that would allow the disabled person to obtain physical and mental self-control. The progress was visible: a greater self-confidence and much greater psychomotor self-control.

The path opened by $\mathrm{Ch}$. Wattelle was continued, including Hatha Yoga as such; V. Pise et al. (4) study is an example. Given the disorders of the motor development and coordination, often found in mental handicapped children (body scheme disorders, perceptual-motor development and coordination difficulties) the target was to obtain a significant progress of the psychomotor coordination through yoga training (loosening exercises, asana, pranayama and meditation); the exercises were introduced in a slow and progressive manner. The program was developed during 12 weeks, 1 hour a day, 6 days in a week. At the end, there were: an improvement in motor skills, eye-hand coordination, static balances and agility. Also, a reduced stress and tension were found.
Within the preoccupations for the use of the Oriental experience we find also the relaxation technique based on traditional Chinese exercises.

Thus, encouraging results were found after one month of training through the Chinese mind-body exercises as self-control enhancing in children with autism spectrum disorders the stress was also reduced and the limb flexibility was increased. The study was carried on 48 children, ages between 6 and 17, all of them showing an improving of their general behavior and also, the cognitive functions (5).

The Autogenic Training constitutes a third relaxation technique used with the persons with disabilities. It is a technique developed by the German psychiatrist Johannes Heinrich Schultz, first time published in 1932. Regarding the influences exerted on the author, there are two completely separate opinions: one considers autogenous training as exclusive derived from suggestion and hypnosis, while a second opinion considers yoga techniques as the basic source. Undoubtedly, in the Schultz technique elements that are closer to the suggestion can be encountered while others are related to the yogic exercises of concentration and relaxation.

Considering the expression "quasi-hypnotic state" not too well-suited here there is the definition of the Autogenic Training given by APA Dictionary: “... a relaxation technique in which a quasi-hypnotic state is self-induced and deep relaxation is achieved through mental imagery, breath control and exercises that focus attention on physical sensations, including warmth and heaviness of the limbs, a regular heartbeat, abdominal warmth and cooling of the forehead. The aim is to reduce stress by gaining control of autonomic arousal associated with anxiety and to obtain an ideal performance state" (6).

The training can be performed in different postures simple sitting, reclined armchair, and horizontal posture. The technique involves several standard exercises, added one by one, according to the stage the individuals were- beginners or advanced.

There is a quite large appreciation of the potential good effect of this technique upon adults and children with problems. There is also a finding that children and adolescents with aggressive, impulsive, attention deficit behavior have benefited from the autogenic relaxation training. A study carried on in 2003 (7) showed good results at the end of the intervention, the subjects being fifty children between 6 and 15 years old, presenting mild disturbed behavior symptoms. 
Finally, we have to stop at a therapeutic alternative that, although based on a serious scientific basis, does not seem to be viewed with proper attention. Unfortunately, like (Hatha) yoga, it experienced an excessive popularization, which rather degrades value than increases it. We encounter this alternative everywhere, used in the most different situations, the experimental base being unclear. Even its name knows many variants. We are talking about Guided Imagery, an alternative that underlines the influence of the psychological state upon the body, more specifically, upon the behavior as it is outsourced. Hence the confusion that sometimes appears between the mental visualization founded in Schultz technique and the guided imagery, the two of them having, no doubt, some elements in common.

In the middle of the last century there was an increased interest of scientists from Europe, the USA and Asia (especially Japan and China), regarding the role of imagination on the health of the person but also on his general attitude, in life. Gradually, the relaxation therapies, the clinical psychology as well as the research in medical sciences have formed an extensive body of knowledge, indicating the influence of the psychological factors upon the physiology of the body. The new therapeutical alternative has considered also the spiritual experience of different religions, yoga and of course, not ultimately, Schultz's Autogenic Training (8). Soon, the Guided Imagery found its utility in children psychotherapy (9).

We found in Leuner and his collaborators (1983) the description of the sessions with subjects of different age and different difficulties. Thus, he reported an experiment including 86 children, between 7 and 16 years old, with pronounced behavioral disturbances. They were divided into several groups close in age, each group having separate but similar meetings. The children were asked to lie down comfortably or sit in an armchair and close their eyes. Then, they were asked to picture an image. The images are all, suggested by the therapist. The therapist supported the visual character of the image with comments and questions. The image is the context which the subjects populate individually, with things and beings, according to their internal psychological condition, revealing in this way, their actual problems.

Here there are the results concerning the behavior only: out of 86 subjects, 10 were extremely restless or tense, 41 were predominantly restless or tense, 22 became gradually calmer and relaxed and 13 became quickly and deeply relaxed. Consider- ing the problems they came with at the beginning of the therapeutic program, the results were no doubt, satisfactory (10).

\section{RESEARCH}

The purpose of reviewing these therapies was first of all, to highlight the similarities between them; all emphasize the importance of the psychic factor in the improvement or disappearance of certain behavioral disorders, the awareness of the body as a whole but also in its segments through relaxation and through sensations, the use of visualization and the imaginary in the process of awareness. Moreover, the aforementioned therapies can be used for both adults and children, regardless - very important - of the coefficient of intelligence. As for the category of subjects we are interested in - children with mental disabilities -, previous studies may not be an important corpus, but in any case it is not to be neglected.

Unfortunately, these therapies and their beneficial effects have not even indirectly entered the field of special psycho-pedagogy, and even less so in educational institutions for children with intellectual disabilities.

Therefore, the objective of our study was firstly to shift the interest from the cognitive aspect, considered excessively in relation to children with mental disabilities, to the emotional and imaginative aspects and secondly, to make this transfer through a relaxation therapy taking place even within the institutional context. Given that, as far as we know, relaxation therapy has never occurred within the school program, our study is rather ascertaining and not one based on a firm hypothesis. However, as a working hypothesis we can consider the following statement: if relaxation therapy has been shown to be beneficial for children with mental disabilities, then it is assumed that this benefit may be manifested also after this type of therapy, carried out within the school institution. Obviously, this assumption is weakened by the multitude of limiting factors existing in an institution.

But, we repeat, being a descriptive study, we can maintain the hope that the final results can be a starting point for a stronger study and hypothesis.

The subjects undergoing therapy are 13 children, boys between the ages of 8 and 11, all being students in the 2 nd grade of a special boarding school for boys. All were diagnosed with mental deficiency with varying degrees of severity. With one exception, all of them have attended the 1 st grade in a mainstream school. 
The subjects of the study were 13 children, boys between the ages of 8 and 11, all being students in the 2nd grade of a special boarding school for boys. All were diagnosed with mental deficiency with varying degrees of severity. With one exception, all of them have attended the 1st grade in a mainstream school. All of them were rejected as being "slow" learners. In some cases, however, the cause was rather an excessive rebellious behavior - running away from school, complete disinterest in any kind of training. In the official documents there was the characterization of the former teacher but not the psychological tests used. All the students came from a less favored environment, from hard working families with numerous children.

Intuitively, based on the observations, on the recording of the way in which the children were capable of learning, noticing also their learning rhythm, the special school teacher was able to identify a few categories of the learning disabilities: 5 children with severe mental deficiency, whose maximum performance was copying with difficulty some words and numbers, but without understanding their significance; 8 children with mild mental deficiency, who had no difficulty adapting to the special school tasks; 1 child being probably in the "slow learner" area due (only) to the slower pace of learning and expelled from the second class of the general school without a clear stated cause; 1 child with above average intelligence but extremely independent and rebellious. Permanently running away from home and from school, a kind of Romanian Huck Finn, it was not difficult to be labeled as mentally deficient, not knowing anything and not responding to any request. The family wanted to "escape" the burden of this child so that no intervention of the teacher could convince the father to get him out of the special school.

With the exception of the student from the second grade of the mainstream school, none of the students could read and write, in fact, no one was even able to identify the letters and numbers.

Another common element of the 13 students was the emotional shock: the sudden change of environment, without explanations, but perceived as a major decrease of their own values-- the direct or indirect information made them understand that they arrived in a school for "fools". Moreover, being a boarding school, the children saw themselves as sentenced to a monotonous life, strictly regulated and especially, they felt extremely vulnerable to the aggression of the older students - aggressiveness in every direction. Most of the students are practically abandoned by families and they were not taken home except for school holidays, obliged by the school regulations. Only three of the subjects were reunited with the family over the weekends.

It goes without saying that fear, tension, the almost permanent alertness, the longing for home and fear of being permanently abandoned (not a groundless fear), the state of "prison" after a previous period perceived as a total freedom, all of these have determined in great measure the behavior of the subjects which from the "unstable" became completely unbalanced.

The only moment of the day, quiet and emotionally secure, consisted of the classroom hours, the teacher being an empathetic and responsible person.

\section{DURATION}

The study was conducted over 30 days, comprising 12 sessions, each session having a maximum of 15 minutes, to which is added the preparation prior to each meeting and the subsequent discussions. All sessions took place in the classroom, with each child sitting at his table (tables placed in semicircles / horseshoes).

The method used was an eclectic one, taking from the techniques discussed above, some exercises: breathing, sitting position, the position of "coachman" (Schultz), sensory visualization, the guided imagery.

\section{DESCRIPTION OF A SESSION}

On the chair, everyone, breathing regularly.

Closed eyes; whoever wants to, put his head on his chest or head on the bench, with the instruction: "as if you were sleeping". The therapist stops a little near each child, gently patting him on the head, saying: "Eyes closed, don't squeeze them, now let's pretend to sleep". This behavior of an individualized contact has secured emotionally the subjects (in general, children can not close their eyes, especially in stressful situations). They have gained trust in the therapist and have collaborated with pleasure in the "dreaming" game.

The therapist reads a text describing a calm, restful landscape, including visual, auditory and tactile perceptions, all being part of the children's life experience. Moreover, the language and syntax used are as simple as possible, to be understood by all children.

During this time, the subjects try to "see" the landscape, to feel the respective sensations. 
After the text is read, the children are allowed to "sleep" for another 5-7 minutes, after which everyone wakes up, stretches, yawns, breaths; it is a moment they like very much.

Each child responds to some previously prepared questions (there is no intervention during the session as some therapists do, see Leuner et al.).

In the last session no text is presented, the children being allowed to "dream" their own dream. The result of this last session shows to what extent the subjects are able to relax after the program exercises.

During the session, each subject is carefully monitored and the behavior is noted. The answers to the prepared questions are compared with the behavior during the relaxation, whether or not they are congruent between them.

The texts are read in a calm, equal voice, without emphasizing any of the elements included. Here is the first text:

"Think about what I'm telling you. It is a beautiful, blue water and you, every one of you, go in a boat. It's quiet and you can only hear the paddles, "clip... clip", in the water. Along the boat, in the water, you see blue fish, with red eyes, with long, beautiful tails. Go by boat, there is peace on the water and only the paddles are heard "clip, clip". Arrive to an island and get off the boat. All over are only flowers, the roses smell, try and smell yourself, how beautiful it smells everywhere!

Go through the grass, lie down on your back and see the clear, blue and clear sky, only a small, white cloud above, a clear blue and blue sky, a small, white cloud.

A bunny came to you. He is good and you pet him. He has a soft and warm fur and your hands are getting warm. Pet his soft and warm fur and your hands are getting warm. The evening came.It's getting dark and cold. You get up, get on the boat and return back".

All the texts present such sunny, gentle, warm landscapes; it is worth mentioning that the meetings were held in late autumn and early winter (November-December).

\section{RESULTS AND DISCUSSION}

We shall briefly present the results of the first four relaxation sessions based on the first text. During this period, being the cold season, due to the flu, there was a variation in the number of subjects. Out of the 13 boys, only 9 participated in all four sessions.

\section{General behavior}

6 subjects: gradually calmer and relaxed

2 subjects: predominantly restless during 2 sessions, the first and the last.

1 subject: always restless but not noisy. He has a special situation (his face and bones mobility are similar to a dog). However he is very kind and there is no rejection from his teacher and colleagues but only from his parents. His IQ could not be determined. His speech is well developed but he always speaks like in trance, narrating as being real, all kind of imaginary situations (all of them related to his family). So, it is interesting that during the whole program he has never been able to take part in the guided imagery stories, as the other children did.

\section{Guided imagery}

- 5 subjects followed the images and were able to describe the things they saw. Of course, their language was not fluent, the syntax had errors but as a whole, they where there, in the imaginary landscape.

- 3 subjects did not follow the images but entered a kind of reverie, expressing their personal feelings/concerns. Which in fact, it was even better than just displaying a relaxation behavior.

It must be noticed, one of them has introduced some new things/images in the last two sessions. In the first one he was restless, in the second he let himself guided by the text but introducing a very strong sensation of coldness. Then, in his reveries some mountains appeared, but he always stopped at their base, not even thinking he would be able to climb them.

The other two boys "dreamt" about something familiar and joyful- they were the lucky ones, leaving the school every weekend while the others were left behind in an empty building.

- Finally, another subject, partially following the narrative, has introduced some very personal images: tanks, fighter jets, war. These images will only be deleted in the last two weeks of the relaxation exercise period. The boy ( 9 years old) came to the school with the strong belief that everybody wanted to steal something from him. Perhaps was his family influence. He was always very tense and ready to defend his "wealth". However, gradually he did relax and left behind his fears.

\section{Sensations}

Warm: the warmth was felt by 5 subjects

Cold: the same 5 subjects stated that they felt cold 
The warm-cold sensations were confirmed not only by the children' affirmations but also, by their own behavior during the sessions, moving the hands as petting the rabbit's warm fur or shivering as feeling the cold air.

Color: all the 8 subjects "saw" the blue, less of the other colors; also there was a doubt if the children really perceived the red of the eyes and the brightness of the fish tails.

Smell (of roses): 2 subjects reported that they have smelled the flowers. They are credible because they had the sensation of beautiful smell and in relation to the following texts that did not contain olfactory sensations.

Noise (paddles): None of the subjects stated that they had hearing sensations.

What is interesting, however, is that the children did not hear, either of them, the noise made by the pupils from other classes or on the hallway. This means that they have experienced a real relaxation.

We will also notice that, throughout the entire program, one sees positive changes in the sense that, the added events - we talk about the personal images expressing tension, aggressivity, are erased and the children completely abandon themselves to the game of "sleep", introducing beneficial images, so that the end of each session is a calm, relaxed one. Only one child, the one with an unusual appearance, did not cooperate in any session, but also, did not disturb it.

Another confirmation of the beneficial results was the fact that during the program and the next month (at least) there were no violent incidents as they had occurred before the start of our program.

\section{CONCLUSIONS}

Although the study included a relatively small number of subjects and especially, it was conducted in a rather limiting environment, we consider that the results are generally encouraging.

\section{REFERENCES}

1. Destrooper J, Vayer P. Influence of Relaxation on the Behavior of Mentally Retarded Children (Introduction of Muscular Relaxation Sessions in an Educational Program for Two Mentally Retarded Children with Neurological Manifestations). Rev. Med. Psychosom Psychol. Med, 1972, 14(1):69-82.

2. Wattelle Ch. Yoga et handicaps mentaux. EPI, Paris, 1975.

3. Wattelle Ch. Yoga, troubles et handicaps. EPI, Paris, 1986.

4. Pise V, Pradhan B,Gharote M. Effect of yoga practices on psycho-motor abilities among intellectually disabled children. Journal of Exercise Rehabilitation, 2018, 14(4):581-585.

5. Chan AS et al. A Chinese Mind-Body Exercise Improves Self-Control of Children with Autism:A Randomized Controlled Trial. Plos One, 2013:8(7).
The first and most important conclusion is that the difficulties determined by the mental handicap do not constitute an obstacle in the course of the relaxation sessions, insofar as they are of course, appropriate to the age and the identified problems.

A second conclusion refers to the ambient of the relaxation exercises, an apparently "unfriendly" environment. However, it seems that, at least in this situation, the classroom environment in which the daily teaching / learning took place did not raise obstacles. The use of a special room for therapy does not always seem to be necessary, although it is obviously advisable.

A third conclusion is generated by the visibly beneficial effects of the guided imagery exercises on children's behavior. We believe therefore that introducing such activities into the school syllabus would be a welcome measure.

Students could not be further tracked in their school itinerary, so long-term effects could not be assessed.

Finally, it is important to emphasize the importance of the emotional side of the personality of children with learning difficulties) not only during possible therapy sessions but also in their education in the family and in school.

An aspect that reinforces the need for such sessions of emotional relaxation and self-control of the behavior is the application of the policy of inclusion of children with disabilities in the mainstream classrooms. Contrary to what is sometimes claimed, their placement in these classes does not improve the IQ, but it can cause strong emotional imbalances, with unpredictable consequences in the subsequent evolution of the child.

We therefore advocate for increased attention and specialized support for equipping the child with learning disabilities, as far as possible, with skills of emotional self-regulation and stress resistance.

Conflict of interest: none declared Financial support: none declared

6. Gary R. VandenBos (Editor). APA Dictionary of Psychology 2nd ed. American Psychological Association, 2015.

7. Goldberg L, Schmidt K. Effectiveness of Autogenic Relaxation Training on Children and Adolescents with Behavioral and Emotional Problems. Journal of the American Academy of Child\&Adolescent Psychiatry, 2003, 42 (9):1046-54.

8. Schultz JH. Le training autogène. P.U.F., Paris, 1972.

9. Hall E, Hall C, Stradling P, Young D. Guided imagery. Creative interventions in Counselling \& Psychotherapy. SAGE Publications, 2006.

10. Leuner H, Horn G, Klessmann E. Guided Affective Imagery with Children and Adolescents. Springer VS, 1983. 